\title{
Compositional Technique and Phenomenological Categories of Perception in the Passacaglia of Shostakovich's Symphony No. 8
}

\author{
lyad Abdelhafeez Mohammad / mmmahod@gmail.com
}

Faculty of Fine Arts, Yarmouk University, Irbid, JOR

\begin{abstract}
This article is an attempt to apply several fundamental phenomenological concepts regarding the perception of sound, and music in particular, to the analysis of a concrete musical composition, the Passacaglia of Dmitriy Shostakovich's Symphony No. 8. We aim at exploring the underlying compositional structures that determine how a musical composition presents itself to consciousness, and how it is perceived. An approach is used that combines the views of two of the most prominent researchers in the field of phenomenology of music, F. Joseph Smith and Don Ihde. Our main concern is the structure of primary perceptions and how the latter are intended as a unified phenomenon (akoumenon). A specifically descriptive method is used to analyze the way in which the music presents itself to us acoustically and how we perceive it as sounding in time. After that reference is made to techniques of composition used to mediate and achieve the described sounding.

As a result our research has revealed a deliberately structured dialectical play of awakened retentions, of fulfilled and unfulfilled protentions, a play with intentionality, touching upon the most subtle mechanisms of perception. The current research has also shown that the categories of musical composition and dramaturgy reflect an underlying dramaturgy of phenomenological categories of perception related to the listener's intentionality. These categories include shifts in the focal-fringe ratio, as the focus of intentionality narrows or broadens in accordance with the auditory field of the music it is intending. They also include shifts between different focal cores as such that we have called regional shifts of focus. On a more fundamental level regional shifts of focus occur between various musical parameters, such as rhythm, tonalitymodality, orchestration, melody, timbre, playing technique. Also, the bidimensional character of sound makes it possible for the noetic act to shift its focus between the roundish and the directional dimensions of the auditory field-shape of the music intended. Finally, we have shown how musical time is thematized as a region of intentional focus by way of a desynchronization of various layers of the polyphonic textures within the framework of the fundamental repetitive structure of the Passacaglia. Shostakovich forms three processes of desynchronization within
\end{abstract}


each of the work's three parts (exposition, development, and recapitulation), each of which starts with a synchronization of the musical material and its layers.

\section{Keywords}

Shostakovich, Passacaglia, tonality, modality, musical parameters, phenomenology, time-consciousness, retention, protention, passive synthesis, focus-fringe ration, desynchronization

The current article is an attempt to apply a number of basic phenomenological concepts regarding the perception of sound, and music in particular, to the analysis of a concrete musical composition, the Passacaglia of Dmitri Shostakovich's Symphony No. 8. We aim at exploring the underlying compositional structures that determine how a musical composition presents itself to consciousness, and thus how it is perceived. We will use an approach combining the views of two of the most prominent researchers in the field of phenomenology of music, F. Joseph Smith and Don Ihde. Our main concern will be the structure of primary perceptions and how the latter are intended as a unified phenomenon (akoumenon). Another poignant question that inevitably arises, but which the scope of the current research does not allow us to investigate, is that of how these structures come to constitute what we call a meaning of the composition as a whole in our consciousness. Thus we will use a specifically descriptive method to analyze the way in which the music presents itself to us acoustically and how we perceive it as sounding in time. After that we will make reference to techniques of composition used to mediate and achieve the described sounding.

Since ancient times the mystic relation between music as sound and the effect it has on humans has been the object of everlasting speculations and interpretations, theories, and teachings. The questions of how sound is perceived, of how sound becomes music that evokes emotions, and of how it acquires meaning for our consciousness, have tormented the human mind since the dawn of what we denote with the word culture. Musicology and phenomenology have been drifting towards each other since the end of the nineteenth century. At that time Carl Stumpf, the forefather of the phenomenology of music, develops in his work Tonpsychologie (Tone psychology, 1890) the notion of tonal fusion to explain the effect of tonal consonances and, in a broader sense, of harmony in general. Approximately two decades later Edmund Husserl uses musical tone as a paradigm of internal time in his work Vorlesungen zur Phänomenologie des inneren Zeitbewusstseins (Lectures on the Phenomenology of the Consciousness of Internal Time, 1928), as well as for his theory on passive synthesis in his work Analysen zur Passive Synthesis (Analyses of Passive Synthesis; first published: Den Haag: Martinus Nijhoff, 1966; on basis of manuscripts 1929-1936). During the post-war decades much research has been done in the field of phenomenology of sound in the general, and in the field of phenomenology of music in particular. Yet these attempts seem to be mostly sporadic notions founded on rather divergent grounds that do not sum up to a general and overall theory related concretely to music and musicology. The current research attempts to tie a number of fundamental and generally accepted conceptions to actual musical material and to the 
compositional techniques applied in it, thus concretizing these conceptions and giving them a more experiential dimension.

\section{Theoretical Considerations}

Phenomenology of sound, or, using F. Joseph Smith's term, akoumenology, is primarily concerned with sound as such, as it presents itself to us, i.e. noematically. As Smith writes, "any merely semantic meaning is secondary to the sound in its noematic significance" (Smith 1979: 100). The same attitude is expressed by Roman Ingarden when he declares that: "the specifically aesthetic questions were to me at that time of secondary importance" (Benson 2009: ix). All other considerations such as theoretical conceptions, historical and biographic facts, as well as semantic categories are temporarily bracketed. This leads to a description of the noema, the composition, as it presents and shows itself. After that reference is made back to the noetic act, to how we perceive the work and how we intend it as one, as a unified entity, and how it constitutes itself as meaningful in our consciousness.

In his study The Experiencing of Musical Sound (1979), F. Joseph Smith examines sound as it is experienced from two interconnected aspects. He combines Husserl's model of time-consciousness with his notions on passive synthesis. According to Husserl, sound is perceived momentarily, i.e. as a sequence of now-moments, in which each moment leaves behind it a trail of retentions or short-term memory instances that slowly weaken until they temporarily vanish into memory. From this "memory awareness" that is a "sublevel of consciousness" it can be recalled either by an active act, or passively, being awakened by an accidental event. On the other hand, sound evokes protentions, i.e. projections towards the future, both in the consciousness of the composer during the act of composition as well as in that of the listener, which open up a horizon of possibilities and expectations that might or might not be fulfilled as sound unfolds. Thus the concept of objective time is replaced by one of "phenomenal time", i.e. appearing time, time as it shows itself (erscheinend). Pieces of music "appear to us and develop over time. Husserl's account of internal time consciousness explains how we are able to experience a phenomenon over time. We 'intend' an object in the moment. Yet that object has continuity for us both because of protentions and retentions" (Benson 2011: 582). The extension of a melody is different from that of a res extensa in that it is the "subject expanding in consciousness, the latter interpreted affectively" (Smith 1979: 101). Time shows itself as an "intentional line of temporal experience" (Smith 1979: 103).

The question that arises is: how is a sequence of now-moments or primary impressions perceived as a whole, a unity? Since a melody is not actively reconstructed and synthesized in consciousness subsequently to the act of listening, but rather enters consciousness as already fused in perception, Smith turns to Husserl's notion on passive synthesis. This latter term is a development of Husserl's mentor Carl Stumpf's concept of fusion or amalgamation (Verschmelzung), which he uses to explain two consonant tones sounding together being perceived as one entity rather than simply as two simultaneously 
sounding separate tones. According to Smith, sound unfolding in time, be it a melody, a musical form, or a whole composition, is perceived as one entity, a unity, as result of a similar process of passive synthesis applied to a sequence of sound-instances. This relative passivity is in the heart of sound perception as such and is based on a unity of the same intuitional intentionality intending a sound entity as a whole at the pre-analytic stage of perception, which has its own type of intentionality, independent of what we call "mental activity". Thus, sound unfolding in time becomes a "progressive building of temporal unity in the consciousness of the composer and the perceiver, a unity held together as primary impression, memory, and expectation" (Smith 1979: 106). This passivity, we must emphasize, is of relative nature as opposed to deliberate mental activity. Husserl uses many terms in his work Analysen zur passiven Synthesis to describe this process in an attempt to designate its mediatory character as located between the traditional understandings of active and passive. A thing "builds itself up" (sich aufbauen), "primordially constitutes itself" (sich ursprünglich konstituieren)", "achieves itself” (sich leisten), "produces itself” (sich herstellen), and "fulfills itself" (sich erfüllen) (Husserl 1968: 140, 144, 201, 359, 369). All these terms evolve later, in Heidegger's Der Ursprung des Kunstwerkes, to become the work of art "putting up" or "establishing" a world (eine Welt aufstellen) (Heidegger 1977: 30).

Another prominent philosopher of music is the American postphenomenologist Don Ihde. In his collection of essays Listening and Voice (2007) Ihde develops a visually oriented model of perception, based on the visual dimension of human experience that he afterwards applies to sound. This model, which he calls the double ratio structure, consists of a focal core-peripheral fringe ratio, or center-field ratio, paralleled by a field-horizon ratio. "Noematically within my visual field there is a 'center' of the clearly and distinctly perceived that shades off into a 'periphery' or 'fringe' of the indistinctly perceived" (Ihde 2007: 37). This noematic structure has a correlative in the noetic act that "displays a central awareness that shades off into the barely aware or implicit consciousness at the 'fringe' of more explicit or focused attending" (Ihde 2007: 38). This ratio may considerably vary according to the intentional act, from an exceedingly "narrow" in a "fine focus", up to a more "widely expanded" focus that drives the fringe farther towards the horizon. The extreme case of the latter is what Ihde calls a field state that is the result of an indifferent "blank stare of boredom", when the "focal core recedes towards the limit of disappearance" (Ihde 2007: 39-40). In the reality of human experience the focus-fringe ratio constantly shifts, according to "interests and occasions", i.e. to noetic and noematic factors influencing the experience. Similar considerations apply to the field-horizon ratio, as the "horizon situates the field which in its turn situates the thing", producing the double ratio of focus-filed and field-horizon ratios (Ihde 2007: 106). So, although the field transcends the thing, it is not synonymous with World. As Ihde points out, the latter is introduced only with the "question of horizons that in turn 'surround' and 'transcend' the field of presence" (Ihde 2007: 74).

When applying this visually-based model to the experiencing of sound, Ihde underlines several fundamental differences, two of which are of primary concern to us in this article. On the one hand, sound as a field-shape is roundish, it is omnidirectional in the sense that it surrounds me, I find myself immersed in it, "music can be so penetrating that my whole body reverberates, and I may find myself absorbed to such a degree that the usual distinc- 
tion between the senses of inner and outer is virtually obliterated" (Ihde 2007: 76). This does not, however, presume the surrounding to be constantly homogenous. On the other hand, sound is directional, in the sense that we perceive it as coming from a certain spatial direction. These two aspects taken together produce a bidimensionality of the auditory field-shape, a copresence of surroundability and directionality.

Apart from these two aspects Ihde characterizes the auditory field as continuous, since there is sound present in any human experience. This noematic continuity, though, results in presence becoming invading and penetrating consciousness, an aspect that leads Ihde to the noetic question of a response to this continuous invasion. Finally, the presence of sound is characterized as lively. Sound is present rhythmically and thus has an essential temporality. "The inner secret of auditory experience (is) the timefulness of sound. The auditory field is not a static field" (Ihde 2007: 83).

After this short theoretical excurse we may now turn to Shostakovich's Passacaglia itself and attempt to describe it as it sounds, in a straightforward and purely acoustic way with as little reference to the score or to the usual theoretical and analytical categories as possible, i.e. in a pre-analytic modus. At the same time we will give a description of transformations occurring in the noetic sphere and how these are related to the composition techniques applied.

\section{The Passacaglia: a Description of Sounding}

Dmitri Shostakovich's Symphony No. 8 was written a few months after the heroic defense of Stalingrad in February 1943. According to Krzysztof Meyer's biography of the composer, Shostakovich began working on the symphony's first movement, lasting around half an hour, on July $2^{\text {nd }}$ and finished it on August $3^{\text {rd }}$ in Moscow. By September $9^{\text {th }}$ the score of the more than one-hour-symphony was finished (Meyer 1998: 254). According to the composer, he wanted to portray the "life of the human soul [...] to reflect man's anxieties, his suffering, his courage, and his joy... to portray him as loving life and freedom" (Sabinina 1976: 201).

The Passacaglia is the symphony's fourth movement and is located between a Toccata and the Finale, designated by Meyer as a Pastorale (Meyer 1998: 257; compare also Orlov 1961, 210; Sabinina 1976: 232). The three movements are performed attacca, and are preceded by the long first movement sonata form (Adagio - Poco piu mosso - Allegro non troppo), and the second movement Scherzo-March. The use of the Passacaglia has, of course, in itself important cultural connotations. As R. Golianek points out in his article Dramaturgical Categories of Expression in Shostakovich's String Quartets, slow tempos and related to them genres in Shostakovich's compositions (he mentions the Elegy, Passacaglia and Funeral March), often comprise "different pathetic funeral expressions [...] of mourning" (Golianek 1998: 513). The Passacaglia makes its entrance at the breaking point of the whole symphony's dramaturgy, its culmination, turning the symphony into a "poem of suffering" (Meyer 1998: 257). It forms the symphony's penultimate movement (Henderson 2000: 53), portraying the "human will, blocking the way of brutal 
and senseless destruction" (Sabinina 1976: 227; compare also Bobrovsky 1962: 155-156). Charlotte Segond-Genovesi points out in her 2009 article La question du sens dans les passacailles de Chostakovitch: vers une interpretation sociopolitique that the "rhythmic figure dotted eighth - sixteenth note strongly refers to the world of the Funeral March" through" scholarly examples such as the Marches funèbres from Chopin's $2^{\text {nd }}$ piano sonata, Beethoven's $3^{\text {rd }}$ symphony and $12^{\text {th }}$ piano Sonata (Segond-Genovesi 2009: 241; compare also Orlov 1961: 208; Golianek 1998: 514). Most soviet researchers describe the movement as reflecting a state of "petrification in front of rigid images of motionless destruction and death" (Orlov 1961, 208; compare also Bobrovsky 1962: 156; Sabinina 1976: 228).

The Passacaglia is written in compound ternary form, alluding to a sonata form, and consisting of an exposition, a development, and a recapitulation followed by a coda. The scheme below illustrates the overall form of the movement and will be useful to us throughout the analysis.

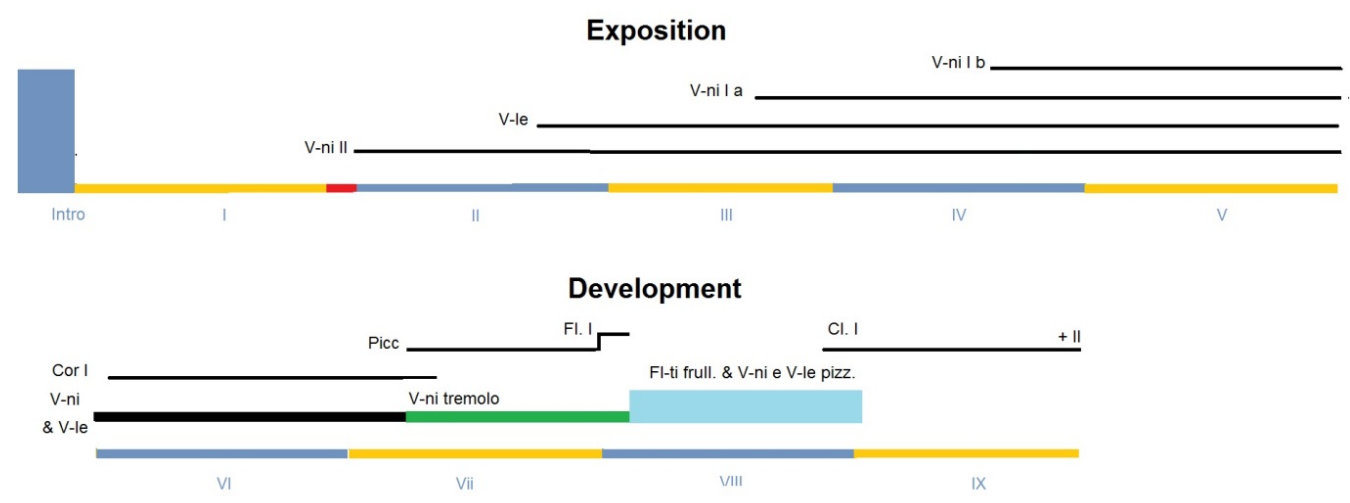

\section{Recapitulation}

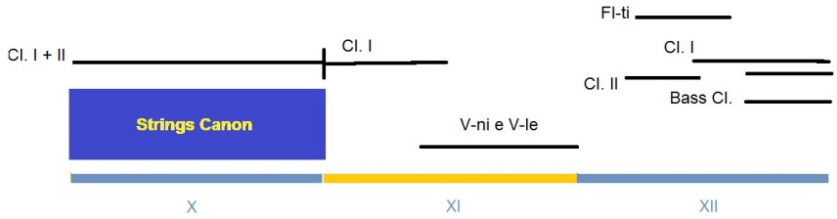

Ex. 1 Formal scheme of the D. Shostakovich Passacaglia, Symphony No. 8.

The Passacaglia opens with a striking triple forte tutti that includes extensive use of percussion instruments. The opening consists of two dissonant chords, the second of which is a major chord on D sharp with an added diminished seventh, and will be resolved on G sharp, the bass theme's first note. These two measures form a short introduction before the bass theme's first statement and, at the same time, a bridge linking the Passacaglia with the previous movement. Shostakovich's abrupt and unforeseen move of the focal center from this highly complicated and loud (invading, penetrating) texture to the unison of the bass theme's first statement demands a rapid and immediate 
change from what Ihde calls a widely expanded focus that nearly occupies the complete auditory field and surrounds, penetrates us, to an extremely "fine" one that directs our attention, and thus our intentionality, towards one, though loud, note. The surrounding auditory field momentarily turns into a distinctly directional one. We experience a sudden "zoom-in", to use a visual metaphor, of our attention. But there also occurs a sudden change of the focus-fringe ratio, a change from an all-encompassing sound to one allowing, despite its loudness and dominance, and due to it being in unison, for accidental concert hall sounds that were not perceptible before to be perceived at the periphery of our consciousness. Thus, in this sudden change from a large dissonant chord to a single unison note we simultaneously experience a shift in the focus-fringe ratio as well as a shift from a roundish to a directional auditory field-shape.

From this note starts the slow unfolding of the Passacaglia's bass theme with its gradually fading retentions and fulfilled or unfulfilled protentions. The theme builds up steadily rising within the ambit of a diminished octave, which is clearly perceived as we reach the higher $\mathrm{G}$ natural (which is in itself an unfulfilled protention in relation to the expected G sharp!), and then descending through a sequence towards the dominant of $G$ sharp, leaping down a perfect fifth to the tonic followed by the leading-note $\mathrm{F}$ double sharp. The overall clarity of the theme's structure makes it easily perceptible as a unity. There are, however, three aspects of it that need to be carefully examined: that of tonality, of rhythm, and of orchestration. As the following description will show, there is a dialectical play with regard to expectations, i.e. protentions, that make it rather unusual and, one may say, akoumenologically interesting.

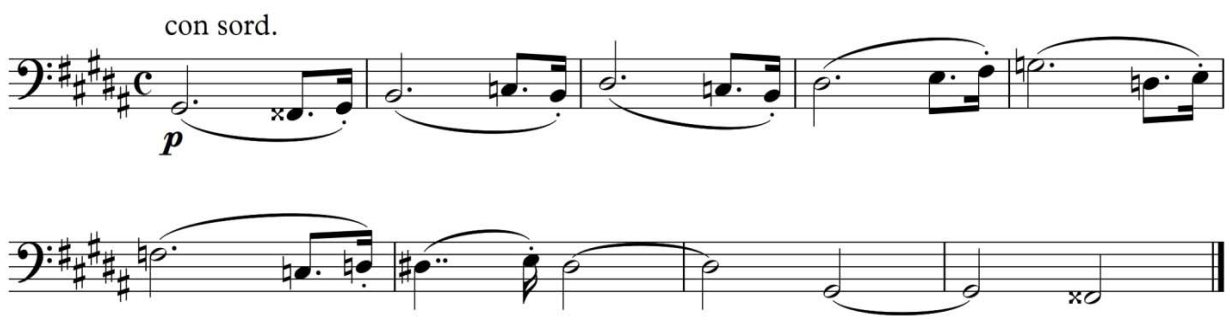

Ex. 2 Passacaglia bass theme.

Regarding rhythm, there is a mutli-leveled repetitive structure embedded in the theme that anticipates the cyclic structure of the movement as a whole. First, there is the rhythmic pattern of a dotted half note - dotted eighth note - sixteenth note that encompasses the first six and a half measures of the nine-measure theme. Second, the fourth measure together with its anacrusis is a literal repetition of the previous measure. This is in itself an interruption of the gradual tonal movement, of the theme's development, and would presumably form an unfulfilled protention, as well as a moment of doubt regarding the coming unfolding of the theme. Third, the sequence in measures five to seven enhances the feeling of the already existing rhythmic repetition through a repetitive melodic pattern, and that at a moment when the rhythmic pattern has itself already 
become to a certain degree tedious. After that, in the middle of the seventh measure, the place where predictability has reached its highest point, the theme loses its gained momentum and determinacy and "gets stuck" on three, tonally relevant but rhythmically vague, long notes, two of them tied across barlines. As M. Sabinina writes, "the [musical] idea seems to be looking for a point of support, from which it can push itself off in order to move on" (Sabinina 1976: 230). All this makes the first six measures of the theme almost unmistakably predictable, up to the last three measures where the established rhythmic structure, not only the specific rhythmic pattern, dissolves into ambiguity.

The tonal plan of the theme is relatively stable, G sharp minor with a lowered fourth degree, characteristic for Shostakovich, is consistent throughout it, with the exception of a sudden deviation in measures five and six to $\mathrm{C}$ major. This shift has two implications: first, it emphasizes the note $\mathrm{C}$ natural, the lowered fourth degree of the scale that defined the modality of the theme from its very beginning, and, second, it leads to the note $\mathrm{G}$ natural forming the already mentioned overall ambit of the theme, a diminished octave. This, of course, disrupts the hitherto stable tonal foundation, again, disappointing formed protentions and evoking new, less confident ones. So, the sequence in measures five to seven has another, adverse side to it other than strengthening the tedious effect of repetition. As Ch. Segond-Genovesi notices, a reiterated sequence in the bass of Shostakovich's Passacaglias is often used as a "pretext (but also as a structural framework) for a subtle game of tonal distortions, which primarily affect the bass itself". As she points out, such distortions are especially valued by the composer "because of the high tension they create and their ability to destabilize the feeling of tonality in the bass" (Segond-Genovesi 2009: 252).

The previous remarks give an insight into how Shostakovich structured his music. There exists a clear complementarity between the rhythmic and tonal aspects of this theme in regard to predictability and the forming of fulfilled or unfulfilled protentions. The composer creates a dialectics of intentionality. For the first four measures Shostakovich allows for both tonality and rhythm to establish themselves before the unexpected tonal shift to $\mathrm{C}$ major for two measures occurs, while the rhythmic pattern remains unchanged. This shift disrupts the just established modal consistency and draws the focus of our attention towards the tonal aspect of the unfolding melody, moving the sphere of rhythm towards the periphery. After that, as soon as we are back to the dominant of $\mathrm{G}$ sharp, that same hitherto unwavering rhythmic pattern is abruptly interrupted and rhythmic predictability dissolves in anticipation. Consequently, the focus of our attention is turned back towards the rhythmic aspect while modality is moved to the periphery of our perception. Such a complementarity and interdependency between various aspects of an akoumenon, in this case modality and rhythm, make it easier for the listener to perceive the theme as a unity, i.e. in its wholeness.

Thus, here we are dealing with a regional shift of focus (in the phenomenological sense of "regional", used by Husserl in his Ideas) when attention shifts from one aspect, element, or parameter of the music to another. Such a description must in no way be understood as dualistic, advocating an absolute duality between pitch and rhythm, since there can be any number of aspects to a musical akoumenon, allowing a great degree of variation to such approximations. 
In respect to orchestration we perceive the first statement of the theme itself as an unfolding variation, albeit a decreasing one, a symbolic retrograde movement, or a $d e-$ construction of the orchestral formation reached at the movement's beginning through previous development. After the opening tutti, the exposition of the theme in unisono starts with the complete brass and string sections with the exception of the doublebass, enhanced by the cor anglais, clarinets, bass clarinet and bassoons. The orchestra is gradually diminished by a step-wise reduction of the brass section followed by the same process simultaneously in the strings and woodwinds, to leave only the 1st violin, viola and bass clarinet at the end. After the theme's exposition the orchestra is, until the end of the movement, limited to the strings, occasionally joined by the flutes, clarinets and first French horn.

This gradual reduction of the orchestra is at the same time a subtle change in timbre. This is very obvious in the interpretations of, for example, M. Rostropovich and $\mathrm{V}$. Gergiev. It is a slow change from the firm military brass sound of the first measures to a more expressive, even lamentous sound in its last notes, bringing us to the sound of the muted strings sustained for the remainder of the movement.

The orchestration of the theme's first statement as a noematic process, thus, leads to a corresponding noetic narrowing of the focal center of the listener's attention, a subtle, yet noticeable change of its focus-field ratio. This example very clearly illustrates the difference in intentionality between perceiving ordinary everyday sounds and listening to music. In everyday life, when attention is focused upon a specific fine sound and the focus-field ratio changes as the focal center narrows and the peripheral part of the field broadens, my intentionality is completely concentrated on the focal center, consciousness tries its best to suppress all other surrounding sounds that threaten to invade it and disturb my perception of the focal akoumenon. When listening to music, on the contrary, the process is much more complicated. For while consciousness does concentrate on the focal center, it simultaneously tries to filter peripheral sounds in perception, to suppress "unwanted" sounds that clearly do not belong to the music, but at the same time to stay open to sounds that may suddenly start sounding at the periphery, and that it does in the broadest range of pitch (register), dynamics, (loudness) and timbre. At this point the listener's intentionality is an anticipating and projecting one. Consciousness is forming peripheral protentions as I hear and anticipate the theme reaching its end. I am intending the center as well as the periphery of the sound field that surrounds me and into which I am immersed.

\section{Statements II-V (Exposition)}

The following four statements of the theme present us with a gradually intensifying texture, thickening and growing more and more dissonant. The second statement is counterpointed by a melodic line in the second violins. This counterpoint is simple, unobtrusive, even passive, and restricted in its expressive means. It consists of only minor and 
major seconds with many chromatic alterations, it is restricted to the relatively small range of a perfect forth, and presents a typical two-voice polyphonic texture where the second voice is imitative and rhythmically complementary to the bass line. Therefore, the focus of attention is constantly shifting between the two voices, the overall structure of the texture is predictable, and no sudden events disrupt emerging protentions, apart from the yet ambiguous last three measures.

In the third statement the beginning of the counterpoint coincides with that of the statement, with a three-beat anacrusis. The texture is still restricted to the same two voices, but here the second violins develop a much more individualized and expressive melodic line that includes larger and consecutive leaps with an overall ambit of two and a half octaves. In addition to its rhythmic diversity, in most measures it emphasizes the anacruses to the following measures, in coincidence with the rhythmic structure of the bass theme. The counterpoint to this statement is the most individualized and the most expressive melodic theme of the whole Passacaglia, alongside the strict and ascetic bass theme. It becomes the dominating focus center while the bass line is distinctly moved towards the periphery, without, of course, losing its unmistakable presence.

Just before the fourth statement, as the violas join in "above" the second violins two and a half measures before its beginning, a vague asynchronicity is starting to be felt. Our attention shifts back to the bass that has clearly not yet reached its end. Rhythmic complementarity between the upper voices and the bass is maintained within an entangled dissonant imitative polyphonic texture that can best be characterized as a countertexture rather than as separate individual contrapuntal melodies. This quiet texture regresses to an even less individualized and expressive level than the counterpoint of the second statement.

Two measures and three quarters of a measure before the beginning of the fifth statement, half of the first violins come in, again "above" the rest of the texture. This entrance confirms the earlier felt asynchronicity. Here the counter-texture almost completely loses all signs of individuation, with the exception of the overtly expressive first measure of the actual statement, reaching the "highest" note yet.

The gradual process of desynchronization is finally established as the second half of the first violins enter almost in the middle of the current statement, three and a half measures before the beginning the of the sixth statement, at the same time strengthening the dissonant character of the already dense texture.

Thus, after the initial unison statement with its decrescendo, deconstruction of the orchestra, and the transformation of its sound, the listener would have experienced a gradual increase of sounding dissonances and overall density of the texture, albeit without any noticeable change in dynamics, countered by a variable, though in general decreasing degree of expressiveness and individuation of the counter-texture. In the examined statements we experience a continuous subtle but detectable alternation of the focus of our attention between various voices, between the bass theme and the countertexture, an incessant interchange between the focus and the periphery that lies in the very heart of polyphonic writing and listening. It is an attempt to grasp the texture in its wholeness by way of passive synthesis of consecutive now-focus-moments. At the same 
time one experiences various focus-field ratios in accordance to the broadening and narrowing of the auditory field due to its intensification or reduction.

\section{Statements VI-IX (Development)}

With the sixth statement of the bass theme a radical transformation of texture and timbre occurs. To mark its beginning the composer resynchronizes the music's main layers, starting a new gradual process of desynchronization and alienation. Shostakovich introduces the French horn on the statement's first measure as the violins and violas form long four-beat dissonant chords determined more by horizontal voice leading than by vertical functionality. The texture is thus divided into three contrapuntal layers: the bass line, the string chords, and the melody of the French horn. All three are clearly perceptible, as each layer has its own beat(s) to emphasize and stress. Thus, the French horn changes notes together with the bass on the first beat and alone on the third beat of each measure. This changes on the last beats of the bass theme, as it starts to lose its dominance and distinctness. As a consequence, a more complex focus-fringe ratio in reached, although the principle of the continuous shifting of attention between layers of the polyphonic texture remains valid. The French horn is clearly the closest to the focal core, the bass theme would be located at a close fringe, while the string chords form a farther fringe. The French horn's melody grows out from a four-note motif and extends more than two measures into the next bass statement, delaying the beginning of the following "variation" and further delinking the textures from each other. Thus there is a clear return to the desynchronization between layers, which will only intensify over the next three bass statements.

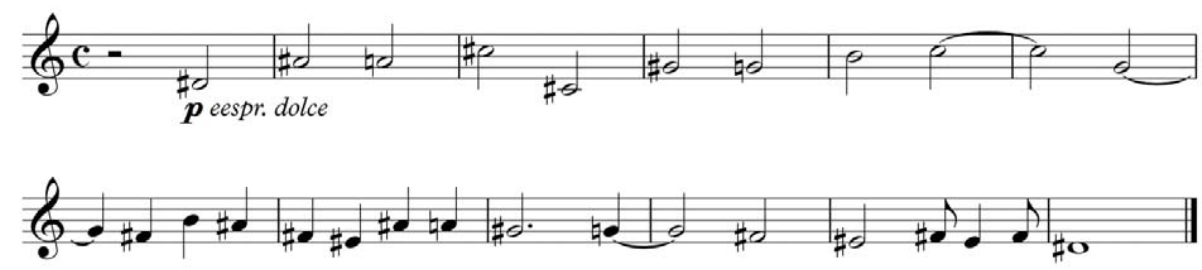

Ex. 3 French horn melody in sixth statement.

The seventh statement introduces new material as well. At the focal core the piccolo plays an ornamental melody consisting mainly of turns or gruppettos around the tonic, dominant, and occasionally subdominant notes of $\mathrm{G}$ sharp minor in fast quintuplets. Towards the end of the statement each last quintuplet becomes tied to the first of the next quintuplet group. As a consequence, the rhythm becomes vague and very much detached from that of the overall texture. Asynchronization is relocated from the layer level to that of rhythm, leading to further alienation between the layers. In the farther fringe, filling the register between the basses and the piccolo, the violins and violas play 
tremolo a perfect fourth doubled in three octaves and chromatically descending over the span of the whole bass statement; a "thick" passus duriusculus leading directly to the following statement of the bass theme.

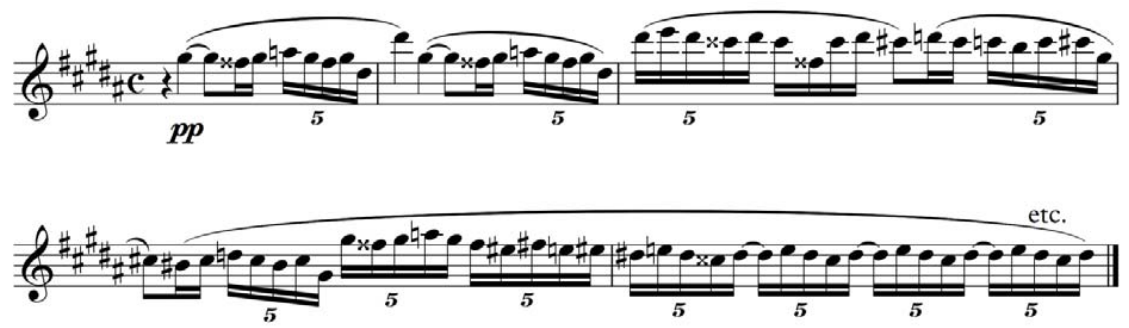

Ex. 4 Piccolo passaggi in seventh statement.

In the eighth statement we see the layers gradually getting back "into place", and, at the same time, "closer together" in register. Here the four flutes combine the tremolo of the previous statement, turning it into a frullato, with the opening motif of the French horn melody from the sixth statement. They are joined by the violins and violas playing the same notes pizzicato. The texture is thus becoming "thinner", more "translucent", and the layers closer both in register as well as in material. Nevertheless, the amorphous character of the flute-strings layer, both as melody and as rhythm, sustains a concrete level of alienation between itself and the bass line. In this statement the focus-fringe ratio is not as clear as previously because the flutes, having started by developing a familiar motif, quickly lose their melodic significance. At the same time the natural imbalance between the weaker frullato of the flutes accompanied by the pizzicato of the strings on the one hand, and the heavy basses on the other, allows for a natural return to the dominating role of the bass theme.

The ninth statement of the bass theme is a simplified, less individual version of the piccolo solo of the eighth, now played by the clarinet. It is situated an octave "lower" and the opening, more characteristic part is omitted, thus introducing the tied quintuplets from the beginning. The "thick" layer of tremolo in the violins and violas is replaced with slow one in parallel thirds. The clarinet solo ends on accented syncopated quarter notes that lead to the next statement and continue throughout it.

Thus, starting with the French horn melody in the sixth statement, Shostakovich introduces two new akoumenological regions to the listener's attention that have previously been relatively absent: those of melody and timbre. Melody has thus far been associated almost exclusively with the bass theme; primarily by ways of its dominance, but also due to the high level of dependency of other counter-melodies on it. This is true as well for the counter-melody of the third statement, despite its originality and individual character. Also essential to determining the content of the region of melody is the strong contrast in character between the melodies of the sixth and seventh statements.

As for timbre, we can say with certainty that it occupies a central place in the focal core of attention of the listener due, mainly, to its novelty, but also to the extreme differ- 
ence between the timbres of the French horn, piccolo, and clarinet. Thus the middle section demonstrates a clear shift from one group of akoumenological regions to another. Shostakovich replaces rhythmic complementarity with contrast of melodies and timbres.

In addition, starting with the seventh bass statement, the composer introduces a further region: that of playing technique. And although it is less significant than that of melody or timbre, it still plays a noticeable role in the formation of the music by, first, transforming the timbre of previously introduced instruments and, second, by contributing to the outlining of the musical form through its return as we shall see later on.

\section{Statements X - XII (Recapitulation and Coda)}

At the beginning of the tenth statement Shostakovich again resynchronizes the polyphonic layers to form a canon between the basses on the one hand, and the violins and violas on the other. Such a polyphonic genre entails a constant shifting of attention from one voice to the other. At the fringe of the audial filed we can barely hear the accented syncopated quarter notes of the two clarinets. Shostakovich makes them deliberately obtrusive, pitch-wise irrelevant, and completely detached. With its clear return to the "pure" theme, this statement forms what can be called a recapitulation, while the remaining two constitute a coda-transition linking the movement to the following one.

In these last two statement of the bass theme the detachment between the latter and the rest of the music is finalized. What we perceive are sporadic fragments of familiar motifs and akoumenological regions that the composer had made the focus of our attention at one point or another. Despite the two complete and consistent statements sounding in the basses, this is a section full of reanimated retentions and anticipating protentions, in which the hitherto dominating theme is moved to the fringe.

\section{Conclusion}

As a result our research has revealed a deliberately structured dialectical play of awakened retentions, of fulfilled and unfulfilled protentions, a play with intentionality, touching upon the most subtle mechanisms of perception. The current research has shown that the categories of musical composition and dramaturgy reflect an underlying dramaturgy of phenomenological categories of perception related to the listener's intentionality. These categories include shifts in the focal-fringe ratio, as the focus of intentionality narrows or broadens in accordance with the auditory field of the music it is intending, as we have most clearly seen in the shift of the focal-fringe ratio between the first two measures of the movement preceding the bass theme's first statement and this latter statement itself. They also include shifts between different focal cores as such, that we have called regional shifts of focus. The simplest example of such a shift is the constant shift of focus between 
different voices or contrapuntal voice-layers when listening to polyphonic texture. On a more fundamental level regional shifts of focus occur between various musical parameters, such as rhythm, tonality-modality, orchestration, melody, timbre, and playing technique. Also, the bidimensional character of sound makes it possible for the noetic act to shift its focus between the roundish and the directional dimensions of the auditory field-shape of the music intended. Finally, we have shown how musical time is thematized as a region of intentional focus by way of a desynchronization of various layers of the polyphonic textures within the framework of the fundamental repetitive structure of the Passacaglia and its overall musical form. Shostakovich forms three lines of desynchronization within each of the work's three parts (exposition, development, and recapitulation), each of which starts with a synchronization of the musical material and its layers.

\section{Bibliography}

BENSON, B. E. The Improvisation of Musical Dialogue. Cambridge: Cambridge University Press, 2009.

BENSON, B. E. Phenomenology of Music. The Routledge Companion to Philosophy and Music. New York: Routledge, 2011, pp. 581-591.

BOBROVSKY, V. Претворение Жанра Пассакальи в Сонатон-симфонических Циклах Д. Шостаковича. [The Reinterpretation of the Passacaglia in the Symphonic Cycles of Shostakovich]. Muzika i Sovremennost, 1. Moscow: State Musical Publishers, 1962, pp. 149-82.

SEGOND-GENOVESI, Ch. La Question du Sense dans les Passacailles de Chostakovitch: Vers une Intérpretation Sociopolitique. International Review of the Aesthetics and Sociology of Music, 2009, 40 (2), pp. 235-268.

GOLIANEK, R. D. Dramaturgical Categories of Expression in Shostakovich's String Quartets. Les Universaux en Musique, éd. Hascher X., Miereanu C. Paris: Publications de la Sorbonne, 1998, pp. 501-518.

HEIDEGGER, M. Der Ursprung des Kunstwerkes. Gestamtausgabe, Band 5, Holzwege. Frankfurt Am Main: Vittorio Klostermann, 1977.

HENDERSON, L. Shostakovich and the Passacaglia - Old Ground or New? The Musical Times, 2000, vol. 141, pp. 53-60.

HUSSERL, E. Analysen zur passive Synthesis. Den Haag: Martinus Nijhoff, 1968.

IHDE, D. Litening and Voice, $2^{\text {nd }}$ edn. Albany: State University of New York Press, 2007.

MEYER, K. Дмитрий Шостаковии [Dmitri Shostakovich]. translated by Gulyaeva E. Saint Petersburg: Kompozitor, 1998.

ORLOV, G. Симфонии Шостаковича [The Symphonies of Shostakovich]. Leningrad: State Musical Publishers, 1961.

SABININA, М. Шостакович - Симфонист [Shostakovich - The Symphonist]. Moscow: Muzika, 1976.

SMITH, F. J. The Experiencing of Musical Sound: Prelude to a Phenomenology of Music. New York: Gordon and Breach Science Publishers Inc, 1979. 